Anuario Latinoamericano Ciencias Políticas

y Relaciones Internacionales

vol. 6, 2018

pp. 263-279

\section{La emigración polaca hacia la Argentina de entreguerras*}

DOI: $10.17951 /$ al.2018.6.263-279

\section{Polish emigration in the interwar Argentina}

\author{
Katarzyna Porada** \\ CONSEJO NACIONAL DE INVESTIGACIONES CIENTÍFICAS Y TÉCNICAS \\ BUENOS AIRES, ARGENTINA \\ $\triangle$ katarzynaporada@gmail.com \\ orcid.org/0000-0002-6161-2065
}

\section{RESUMEN}

El periodo de entreguerras constituye una época destacada en los movimientos poblacionales entre Polonia y Argentina. Se calcula que en dos décadas emigraron a este país latinoamericano aproximadamente 160 mil ciudadanos polacos. La época de entreguerras y particularmente los primeros años de la década de los treinta constituyen también un periodo de gran vulnerabilidad y muy alta desocupación observada entre los inmigrantes polacos, fenómeno especialmente visible en el contexto porteño. Centrándonos en este caso particular, el presente artículo pretende analizar qué consecuencias tuvo el periodo de la crisis económica sobre este grupo, así como la imagen del inmigrante polaco que se fue construyendo en la capital argentina en el periodo señalado.

PALABRAS CLAVE: Argentina, periodo de entreguerras, inmigración polaca.

\section{ABSTRACT}

The interwar period is an outstanding time of population movements between Poland and Argentina. It is estimated that in approximately two decades about 160 thousand Polish citizens emigrated to this Latin American country. The interwar period, and particularly the early 30 s, is also a time of great vulnerability and high unemployment observed among Polish immigrants, especially in Buenos Aires. Focusing on this

* Este artículo se inserta en el marco del proyecto de investigación HAR2012-33147 y HAR2015-63689-R, financiados por el Plan Nacional de I+D+i del Ministerio de Economía y Competitividad de España.

** Máster y Doctorado en Estudios Latinoamericanos por la Universidad Autónoma de Madrid. Licenciada en Estudios Ibéricos e Iberoamericanos por la Universidad de Varsovia. Estancia postdoctoral en el Consejo Nacional de Investigaciones Científicas y Técnicas (CONICET) en Argentina. Autora del libro Procesos de formación de la identidad étnica de un grupo de origen inmigrante en Argentina. Los descendientes de polacos en Buenos Aires y Misiones, Madrid 2016. 
particular case, the article analyzes the consequences that the economic crisis had on this group and the image of the Polish immigration that was constructed in Argentina's capital during that period.

KEYWORDS: Argentina, the interwar period, Polish immigration.

Los veinte años que separan el fin de la Primera y el inicio de la Segunda Guerra Mundial constituyen un periodo destacado en la historia de los movimientos poblacionales originados desde las tierras polacas. Se trata de una época de la política emigratoria dirigida y abiertamente patrocinada por el Estado polaco. En este contexto, Argentina, junto con Alemania, Francia, Estados Unidos y Canadá, se convierte en uno de los principales países receptores para las masas migratorias polacas. Al mismo tiempo, el periodo de entreguerras y particularmente los primeros años de la década de los treinta -época de la Gran Depresión desatada a nivel mundial-, constituyen uno de los periodos más complejos en la historia de la inmigración polaca en este país. En el presente artículo nos proponemos reconstruir esta etapa. Estudiaremos cómo la crisis afectó a este grupo particular y cuáles fueron las medidas tomadas para atenuar, aunque fuera parcialmente, su situación. Paralelamente, analizaremos cómo fue percibida la inmigración polaca en la capital argentina en el periodo señalado ${ }^{1}$.

\section{Polonia y los movimientos migratorios}

En 1918, después de 123 años de la inexistencia en el mapa mundial, Polonia recuperó la independencia. Pronto resultó evidente que el país estaba pasando por un periodo de una gran inestabilidad política y económica, a la que se fue sumando, además, una alta desocupación y la acelerada precarización de las condiciones de vida. En estas circunstancias, el gobierno polaco empezó a poner mayor interés en promover la emigración, percibida como una forma eficaz de hacer frente a los problemas sociales y nacionales que aquejaban al país. De acuerdo con las iniciativas oficiales, desde la década de los veinte, empezaron a fundarse oficinas emigratorias, destinadas a brindar apoyo a los que tomaron la decisión de emigrar, informar sobre las posibilidades laborales en los países de destino y también elaborar informes

1 El presente artículo se basa en el análisis de la prensa polaca publicada en la Argentina de entreguerras ("Głos Polski", "Niezależny Kurier Polski w Argentynie” y "Kalendarz Polski", suplemento publicado anualmente por "Niezależny Kurier Polski w Argentynie"), en la documentación recopilada por las organizaciones étnicas, así como en las publicaciones polacas sobre Argentina editadas en la época. Paralelamente, nos basamos en la información extraída de las publicaciones argentinas del periodo analizado (memorias de organismos oficiales, principalmente de la Junta Nacional para Combatir la Desocupación, en los testimonios de los actores contemporáneos a los hechos estudiados y en la prensa local). 
sobre los procesos migratorios (Nalewajko 2014: 139-45). Paralelamente, fue iniciada la construcción de la ciudad portuaria de Gdynia y, a partír de la década de los treinta, se inauguró la conexión directa entre la ciudad polaca y los puertos latinoamericanos, como Río de Janeiro, Santos y Buenos Aires (Smolana 1983: 45). Además, para facilitar el traslado, se instauró una red de hoteles que albergaban y ofrecían manutención a los futuros emigrantes antes de emprender el viaje.

Como consecuencia de la inestabilidad general vivida en Polonia y debido a las iniciativas proemigratorias gubernamentales, en el periodo analizado, los movimientos migratorios entre ambos países aumentaron considerablemente. El número de 2,4 mil ciudadanos polacos que arribaron al puerto argentino en el año 1921 creció a más de 14 mil en el 1926, llegando a superar la cifra de 20 mil ingresos anuales entre 1928 y 1929 (Smolana 1983: 56). El crecimiento sostenido de los movimientos migratorios entre ambos países quedó interrumpido en los primeros años de la década de los 30. En consecuencia, la inmigración polaca hacia Argentina disminuyó de manera considerable, manteniéndose en esta época a nivel de dos mil ingresos anuales. Tras un periodo de estancamiento, la recuperación económica de Argentina contribuyó a que la intensidad del proceso migratorio empezara a restablecerse nuevamente en la segunda mitad de los años treinta. En consecuencia, se calcula que en aproximadamente dos décadas emigraron a la Argentina entre 157 y 167 mil ciudadanos polacos (Smolana 1983: 56).

Una parte de los arribados en este periodo se radicó en las comunidades polacas creadas ya antes de la I Guerra Mundial. Este fue el caso, por ejemplo, de los inmigrantes que se dirigieron a la provincia de Misiones, donde desde finales del siglo XIX se fueron fundando varias colonias polacas. Un porcentaje significativo se estableció en las ciudades de Córdoba, Rosario, Santa Fe o en la austral Comodoro Rivadavia. La mayoría, sin embargo, optó por quedarse en la capital y en las ciudades periféricas. De ahí, en el periodo de entreguerras, se hizo visible la presencia polaca en las localidades de Dock Sud, Llava1lol, Valentón Alsina y, principalmente, en Berisso, una localidad alejada 60 kilómetros de Buenos Aires. Es esencial aclarar, sin embargo, que dentro del grupo registrado bajo esta categoría, los de origen polaco constituían aproximadamente un 50\% del total de los arribados; el resto fueron los judíos y los ucranianos, considerados por las autoridades polacas como las minorías más conflictivas y los principales culpables de la desastrosa situación por la que pasaba el país (Mazurek 2006: 92).

\section{La crisis y la inmigración polaca en Argentina}

El estallido de la crisis en los Estados Unidos, en el año 1929, pronto se expandió a prácticamente todo el mundo industrializado, siendo uno de sus impactos más evidentes una fuerte y prolongada caída de la actividad económica 
y la consecuente muy alta tasa de desocupación. Este proceso también afectó fuertemente a Argentina, provocando un derrumbe de los precios de los principales productos de exportación -cereales, lino y carnes- y el alarmante aumento de los trabajadores desocupados (Korol 2001: 22). Las consecuencias de la crisis, más visibles en las grandes ciudades, afectaron a toda la sociedad argentina, pero, sobre todo, a los trabajadores extranjeros. Dentro de este panorama, los ciudadanos polacos fueron uno de los grupos étnicos que más padecieron las secuelas de la depresión. En el año 1930, la tercera parte de todos los inmigrantes polacos en la Argentina se encontraban sin trabajo, y los que consiguieron conservar el empleo, trabajaban de forma discontinua o sufrían cortes importantes en el salario (Klarner-Kosińska 1983: 232). Esta situación fue empeorando sucesivamente en los años siguientes, alcanzando su apogeo en 1933.

Como consecuencia directa de la crisis económica vivida en la capital argentina y dado el creciente número de los trabajadores desocupados, desde el inicio de la década de los 30, en los galpones vacíos ubicados en la zona portuaria, se estableció el primer asentamiento informal, construido y poblado mayoritariamente por personas de origen extranjero. Debido a su fuerza numérica, los desocupados pronto comenzaron a poblar los terrenos baldíos de la costa del Río de la Plata, entre las calles Canning (actual Avenida Scalabrini Ortiz) y Avenida Sarmiento, dando origen a la popularmente denominada Villa Desocupación. De esta forma, se fueron levantando lo que un testigo ocular definió "rudimentarias, pequeñas, bajas y antihigiénicas casuchas, inmundas pocilgas más bien, de los más diversos tipos, juntas entre sí, en varias hileras y formando calles angostas" (Ré 1938: 66). El perfil de los habitantes del asentamiento se presentaba relativamente homogéneo. Se trataba de hombres, en su mayoría jóvenes, cuyas edades oscilaban entre 25 y 45 años, que "con sus precarias y deshechas ropas ofrecían un aspecto sucio y de abandono lamentable" (Ré 1938: 68). Los desocupados crearon sus propias secciones, que reflejaban una división según la nacionalidad. La mayoría eran ciudadanos polacos:

En el denominado Puerto Nuevo de Buenos Aires están las barracas de los desocupados. El número de los polacos que viven allí algunos lo calculan como varios centenares otros como varios miles. (...) Se trata de la gente pobre a la que la desocupación y la crisis llevaron a una situación sin salida. [traducción de la autora]

(“Głos Polski”, no 873, 4.12.1933: 4)

La inestabilidad vivida por los trabajadores, en general, y la extrema pobreza de los inmigrantes polacos, en particular, fue un tema recurrente en las notas publicadas por la prensa polaca. En las páginas de los periódicos abundan las imágenes de centenares de inmigrantes polacos sin ocupación, desnutridos y dedicados a la mendicidad en la zona de Retiro y en el centro de 
la ciudad. Los periodistas subrayaban, además, la gran facilidad con que éstos terminaban, durante cada vez más prolongados periodos de desocupación, a formar parte de uno de los precarios asentamientos. En estos términos lo describe "Głos Polski", una de las principales publicaciones polacas:

De este laberinto de miseria absoluta, del que no existe salida, de este oscuro down town bonaerense, emergen a diario miles de personas desesperadas (...), se dispersan por las calles de la ciudad y de los suburbios, mendigando por un trozo de pan para saciar el hambre. Ya no tienen esperanza de encontrar trabajo. Durante meses se presentaban ante las puertas [de fábricas, talleres] en las que siempre encontraban el letrero 'no hay vacantes'. La mayoría de ellos era gente tranquila, razonable, dispuesta a trabajar, pero la miseria les obligó a bajar, cada vez más, y desesperados fueron alimentando el ejército de los infelices. ¿Debería sorprender que en estas circunstancias muchos se convirtieron en enemigos de la sociedad $y$, en vez de buscar en vano el trabajo, se dedicaron a mendigar? [traducción de la autora]

(“Głos Polski”, no 1085, 18.08.1934: 4)

Sorprendidas o no, las autoridades argentinas no permanecieron sin respuesta. Ante la escala de la mendicidad, el gobierno optó por tomar medidas represivas. Consecuentemente, según la ley aprobada en 1932, los mendigos o los que explotasen la mendicidad podían quedar reprimidos con una multa o con el arresto de 6 a 21 días. Según las fuentes policiales, los ciudadanos polacos iban ganando cierto protagonismo en esta actividad. Como se ha podido comprobar, en el año 1933 fueron detenidas 440, en $1934-223$ y en $1935-$ 230 personas de nacionalidad polaca por ejercer la mendicidad. Es necesario destacar que la cifra de los ciudadanos polacos arrestados por este motivo, principalmente hombres, supera a cualquier otro grupo migratorio (Ré 1938). La omnipresencia del problema también fue relatada por Juan Alejandro Ré, subcomisario de la comisaría 23, responsable del área en la que estaba localizado el campamento de los desocupados. Según el funcionario, el clima vivido en la Villa Desocupación ofrecía un contexto altamente propenso para la mendicidad y ésta, a su vez, constituía un punto de partida para cometer todo tipo de infracciones a las normas legales establecidas. Esta situación la fomentaban, en opinión de Ré, la venta de alcohol, la habitual embriaguez de los habitantes y, sobre todo, las quinielas que gozaban de gran popularidad entre los desocupados:

Como era de esperar, resultó este campamento un foco de infección material y moral, donde en escala ascendente y peligrosa se transformaba sucesivamente el desocupado en mendigo, éste en vago, y el vago en delincuente (...).
La emigración polaca hacia la Argentina de entreguerras

Katarzyna Porada 
El fragmento citado refleja la proximidad que supuestamente existía entre los desocupados temporarios o crónicos y la delincuencia; asociación propia de la criminología positivista y que, a su vez, ha permanecido durante décadas en el imaginario social porteño (Daniel 2013: 205). Según éste, la conversión de un desocupado en delincuente era solamente cuestión del tiempo. Cabe destacar que el análisis del autor no se detenía en este punto. Como recalcaba el subcomisario, la pobreza -entendida como la principal causa de desmoralización y delincuencia- iba de la mano con todo tipo de las "ideologías subversivas", transportadas al suelo argentino por los agitadores extranjeros. De esta forma, consecuente con la idea, y al referirse a la Villa Desocupación, Juan Alejandro Ré afirmaba: “se cobijaron allí, además, sujetos de toda ideología, extremistas, comunistas, anarquistas, etc., actividades disolventes que pudieron desarrollarse favorecidas por el ámbito propicio como pocos" (Ré 1938: 69-70).

La identificación existente entre los infractores del orden público y los habitantes de la villa, entre los que, como hemos señalado, sobresalían numéricamente los ciudadanos polacos, lo comprueba también la prensa étnica. No obstante, en este último caso se trató de demostrar la equivocación del prejuicio. De esta forma, uno de los periodistas polacos describe, con cierta ironía, a los habitantes del campamento:

La mayoría son europeos, principalmente rubios o de pelo castaño. Los argentinos los toman por revolucionarios o anarquistas, sin embargo se trata principalmente de la gente pobre, cuyo mayor delito es no tener dinero. (...) En Argentina, entre ciertos grupos sociales, se ha extendido un prejuicio hacia los rubios. Así que mejor pronto volverse canoso o calvo. [traducción de la autora]

(“Głos Polski”, no 873, 4.12.1933: 4)

El asentamiento de los desocupados, a pesar de ser percibido como "foco de infección material y moral", fue tolerado durante varios meses. No obstante, ante los actos delictivos, ocurridos a finales del año 1933 y principios de 1934, las autoridades se vieron obligadas a tomar medidas drásticas. Nos referimos a una serie de atracos a almacenes y tiendas alimenticias en la proximidad de la calle Santa Fe, que ocasionaron importantes daños materiales en los negocios de la zona. Los sucesos fueron protagonizados por los habitantes de la villa, armados de revólveres, hierros, palos y piedras, que posteriormente quedaron identificados como ciudadanos polacos. Esta vez no se trataba de pobres inmigrantes sin recursos, sino de un grupo organizado que, a los ojos de las autoridades, amenazaba la seguridad ciudadana y perturbaba el orden público. Además, la gravedad del asunto radicó en que, según informaba la prensa local, junto con los detenidos, los funcionarios de la policía encontraron numerosos volantes y folletos de propaganda anarquista ("La Prensa" 4.11.1933: 12). 
La comunidad polaca, incapaz de negar la participación de sus compatriotas en los actos vandálicos, optó por asegurar que los individuos que participaron en los asaltos fueron, indudablemente, víctimas ingenuas e inocentes, contratadas por la competencia de los negocios de la zona, ansiosa por destruir, sea como fuese, al contrincante comercial. Tampoco faltaron voces que señalaban que se trataba de un complot internacional que pretendía desacreditar el buen nombre de Polonia y de los polacos ("Głos Polski”, no 867, 27.11.1933: 1). En cualquier caso, el componente ideológico asociado al asentamiento lo convertía en un peligro inminente para la sociedad y no podía ser tolerado por las autoridades. Como consecuencia, en enero de 1934, con intervención de los funcionarios de la policía, los desocupados con antecedentes penales quedaron detenidos y los demás fueron obligados a trasladarse a los galpones del Puerto Nuevo. Al mismo tiempo, los obreros municipales procedieron al derrumbe del asentamiento (Ré 1938: 78).

Si bien la Villa Desocupación destacó por su extensión y el número de habitantes, ésta no fue la única zona de Buenos Aires donde se agruparon los desocupados. La escala de la crisis económica provocó que los asentamientos informales también empezaran a formarse en los bosques de Palermo, en el Parque Patricios o en el Bajo Belgrano (Snitcofsky 2013). En estas circunstancias, las autoridades se vieron obligadas a actuar no sólo de forma represiva, como fue en el caso de los intentos de combatir la mendicidad, sino también tomaron una serie de medidas que pretendían mejorar la situación vivida por los miles de desocupados.

\section{El gobierno argentino ante la crisis}

Aunque la irregularidad e inestabilidad de la actividad laboral era una característica propia del mercado de trabajo argentino a finales del siglo XIX-principios del XX y formaba parte de la vida obrera habitual, la expansión industrial experimentada por el país en las décadas posteriores se ha reflejado en la estabilización del empleo y en los avances en materia de la legislación laboral (Daniel 2013: 210). Es por ello que el importante deterioro de las condiciones laborales en la década de los treinta despertó mayor preocupación que las crisis anteriores. Como respuesta, el gobierno golpista de José Félix Uriburu optó por reducir el gasto de Estado, disminuyendo los salarios de los empleados públicos y restringiendo el gasto en obras públicas. Al mismo tiempo, se procedió a incrementar los impuestos internos y aumentar los aranceles a las importaciones (Korol 2001: 29). Posteriormente, durante la presidencia de Augustín Justo, con el objetivo de proteger la producción agrícola, a partir de 1933 fueron organizadas la Junta Reguladora de Granos, la Junta Nacional de Carnes, la Junta Reguladora de Vinos, la de la Industria Lechera, la Comisión Reguladora de la Producción y Comercio de la Yerba Mate y la Junta Nacional del Algodón. En esta misma época, el gobierno creó también un nuevo 
fondo nacional de vialidad destinado al estudio, trazado y construcción de caminos y obras anexas; iniciando, de esta manera, una época de desarrollo de carreteras que no se igualaría por décadas (Ballent y Goreli 2001). Con la implementación de las obras públicas a gran escala se pretendía, siguiendo el ejemplo estadounidense, crear puestos de trabajo para miles de desocupados y combatir la depresión.

Por otro lado, además de las acciones efectuadas para subsanar la economía nacional, también se tomaron pasos para paliar la situación de miles de desocupados que residían en el país. En este sentido, una de las medidas más importantes fue la creación, en noviembre de 1934, mediante la Ley 11.896, de la Junta Nacional para Combatir la Desocupación. El objetivo de esta, que funcionaría hasta 1944, consistió en establecer las soluciones para el problema, así como encontrar las causas más profundas de la crisis ${ }^{2}$. Se procuró ofrecer la asistencia social a los más necesitados, facilitar el traslado a los jornaleros o peones hacia zonas carentes de trabajadores, formar a los desocupados sin profesión, promover el establecimiento de las colonias agrícolas y, por último, concentrar en campos especiales a los individuos sin aptitudes ni deseos de trabajar (Junta Nacional para Combatir la Desocupación 1938: 15).

La Junta quedó a cargo del albergue donde fueron trasladados los desocupados desalojados de la Villa Desocupación. Allí se les facilitó la comida y la asistencia sanitaria. Para evitar que el albergue se convirtiera en el asilo gratuito, sus habitantes fueron obligados a realizar determinados trabajos. Paralelamente, en las proximidades del mismo se creó la EscuelaTaller con cursos de ebanistería, carpintería, cincelado, herrería artística y encuadernación, así como una chacra destinada al cultivo de las hortalizas. Además, junto con las labores asistenciales, la formación de los desocupados y ayudas para la movilidad, se puso en práctica la exclusión ejemplificadora y el disciplinamiento como medidas para corregir la situación (Girbal-Blacha 2003: 29). Consecuentemente, según leemos en la Memoria elaborada por la Junta:

Numerosos desocupados, cuyo estado de abulia y de desidia permitía dudar de su regeneración, se han convertido en seres útiles, capacitados de nuevo para reanudar la lucha por la vida, volviendo a mostrarse dueños de este bagaje indispensable de la voluntad, sin el cual es imposible iniciar empresa alguna en la tierra. Se han registrado cosas en que el albergado, después de haber caído en un estado de abulia lindante con el de la atonía física y moral,

2 Una de las causas detectadas por la Junta como desencadenante de la desocupación masculina fue el trabajo femenino. Según podemos leer, se trataba de una acción perturbadora para la economía, por recibir la mujer un sueldo menor que el del hombre por el mismo trabajo. Paralelamente, como la actividad laboral implicaba el alejamiento del hogar, ésta tenía un pernicioso influjo sobre la familia (Junta Nacional para Combatir la Desocupación 1938: 26). 
se reintegraba a la existencia higiénica y laboriosa del trabajador, consciente de su recuperada condición de hombre, de elemento productivo y útil para la sociedad.

(Junta Nacional para Combatir la Desocupación 1938: 17)
La emigración polaca hacia la Argentina de entreguerras

Katarzyna Porada

Como podemos ver en el fragmento citado, los iniciadores y ejecutores del proyecto quedaron plenamente satisfechos con el cumplimiento de los objetivos propuestos. Lo acertado de operar en diferentes niveles, como indicaban, consistió en la "reeducación" de muchos de los desocupados, convirtiéndolos en "elementos productivos y útiles para la sociedad".

\section{La comunidad polaca ante la crisis}

Dada la magnitud del problema de la desocupación y el origen de los principales afectados, también la comunidad polaca puso en práctica una serie de medidas que pretendían paliar, aunque fuera en forma parcial, la situación por la que pasaban los connacionales más desfavorecidos. En este contexto, tanto el ya mencionado "Głos Polski" como "Niezależny Kurier Polski w Argentynie", dos principales publicaciones polacas de la época, asumieron el papel de voceros de la comunidad y reclamaban mayor apoyo para los desocupados. Como resultado, ya en 1928, con ayuda económica del cuerpo diplomático polaco, en la ciudad de Buenos Aires, fue fundado el Patronato, entidad dependiente de la Oficina de Emigración en Polonia. Sus funciones consistían en actuar como agencia de colocación, servir de apoyo jurídico o sanitario a la cada vez más numerosa comunidad, intermediar entre el empresario y el trabajador, ayudar a los ciudadanos polacos sin recursos, organizar los comedores sociales gratuitos e incluso facilitar, en casos extremos, el retorno a Polonia. La gran concentración de los inmigrantes desocupados en el barrio de Retiro y en la proximidad del Puerto Nuevo motivaron a los activistas polacos a establecer la oficina del Patronato en la calle Charcas 418, hoy Marcelo T. de Alvear 418. Pese a sus esfuerzos, la enorme escala de la crisis superó las escasas posibilidades del Patronato. Según los datos disponibles, en 1930, de las 5.977 solicitudes de intermediación en la búsqueda de empleo, pudieron resolverse favorablemente 706; en el año siguiente, esta cifra se redujo a tan sólo 458 (Klarner-Kosińska 1983: 232). Al mismo tiempo, las quejas constantes de los que acudían a la entidad en busca de ayuda apuntaban que los trabajos a los que la entidad brindaba el acceso eran o los peor pagados o los más duros y peligrosos.

La escasa oferta laboral que ofrecía el Patronato abarcaba, sobre todo, el servicio doméstico (mucamas, mozos, cocineros, jardineros o choferes). La remuneración oscilaba entre 35 y 100 pesos mensuales, siendo los choferes los mejor pagados. El contratado recibía, en la mayoría de los casos, el alojamiento y la manutención. En segundo lugar, podían encontrar trabajo los peones rurales u obreros de las cuadrillas, equipos destinados para 
la construcción de los carriles ferroviarios. Su remuneración oscilaba entre 25-40 pesos mensuales en el caso de los primeros y 2,20-2,50 pesos diarios, en el de los segundos (“Głos Polski”, no 1012, 19.05.1934: 2). Los que menos dificultades tenían a la hora de encontrar trabajo eran los obreros cualificados. Es por ello que muchos de los inmigrantes polacos, con poca o ninguna experiencia, y con el objetivo de conseguir cualquier empleo, se hacían pasar por profesionales. Según las denuncias de los funcionarios del Patronato, esta práctica, al parecer bastante común, contribuía al mantenimiento de la ya muy dañada imagen del trabajador polaco y de la reticencia de los empleadores a la contratación de las personas de este origen.

También en 1928, gracias a las donaciones particulares y al apoyo de la Legación de la República Polaca en Buenos Aires, fue construido el albergue para los inmigrantes polacos sin trabajo y sin techo. El edificio de un solo piso, situado en la calle Quirno 928, en el barrio porteño de Flores, constaba de dos salas grandes y cuatro pequeñas, dos cocinas y un baño. El albergue, según los iniciadores del proyecto, tenía la capacidad de alojar de hasta 120 personas (“Głos Polski”, n. 23, 24.06.1928: 4). No obstante, la escasez de fondos para su mantenimiento, el alejamiento del centro y de las entidades polacas, provocó que éste, al parecer, no gozara de gran popularidad entre los propios inmigrantes, incluidos los más necesitados, ganándose el nombre del "Hotel Miseria" ("Głos Polski”, no 521, 1.10.1932: 2). Durante varios años, el edificio fue objeto de quejas constantes, que señalaban las condiciones insalubres y la falta de higiene básica. En el informe de la Federación "Dom Polski", el organismo central de la comunidad polaca, encontramos esta descripción del albergue:

El edificio, dada su construcción defectuosa, no cumple con su finalidad. Las salas, oscuras y bajas, no son higiénicas. Los pasillos, angostos y oscuros como en un sótano, hacen que la casa se parezca más a un viejo conventillo que a un albergue. A estos defectos generales se suma el mal acabado del edificio y los arreglos necesarios sobrepasan las capacidades financieras de la Sociedad. [traducción de la autora]

(Federacja Towarzystw i Org. Dom Polski 1935: 22-23)

También por iniciativa de la comunidad polaca en Buenos Aires, en la cercanía de la zona de Retiro, fue fundado el comedor gratuito. En el momento de la apertura, los entusiasmados iniciadores del proyecto aseguraban que éste tenía una capacidad de preparar entre 500 y 600 almuerzos diarios. En realidad, por la escasez de fondos disponibles, llegó a preparar entre 80 y 150 comidas diarias. Por la misma causa, el comedor gratuito de Retiro cerró sus puertas en noviembre de 1931; es decir, después de apenas 8 meses de funcionamiento (“Głos Polski”, no 43, 22.11.1931: 1). Paralelamente, se intentó buscar alternativas factibles y duraderas fuera de la provincia de Buenos Aires que, como denunciaba la prensa étnica, había perdido la capacidad de absorber la mano de obra desocupada: 
La ciudad [de Buenos Aires] es la pérdida de nuestros emigrantes. Así es como ocurre con casi todos los recién llegados: se van al interior, enviados por la Dirección de Inmigración, por el Patronato o por una de las instituciones privadas de este tipo. El trabajo suele ser muy malo y se asemeja a una simple explotación. Lo dejan después de algún tiempo y regresan, a menudo a pie, a Buenos Aires, donde está la Legación, el Patronato, etc., pensando que con ayuda de Dios todo se arreglará. Allí está el problema. [traducción de la autora]

(“Kalendarz Polski” 1932: 118)

Para aliviar la situación de sus compatriotas de la capital, los impulsores del proyecto se dirigían a las comunidades radicadas en el interior del país y, particularmente, a los "hermanos polacos de Misiones" ("Głos Polski”, no 788, 23.08.1933: 1). El nordeste argentino se presentaba, frecuentemente, como una posibilidad viable de escaparse de la desocupación y de la miseria vividas en las grandes ciudades. Así, por ejemplo, en un artículo del año 1933, titulado Misiones, la tierra prometida para los colonos polacos: Polana, referente a la colonia fundada un año antes, podemos leer: "La tierra de Polana es idónea para la explotación agraria intensiva, la única que en la actual época de crisis puede garantizar importantes ganancias sin gran inversión inicial y con relativamente poco trabajo [traducción de la autora] ("Kalendarz Polski" 1932: 213).

Ante las penurias vividas por miles de inmigrantes polacos, empezaron a aparecer voces señalando que la causa de esta situación estaba estrechamente relacionada con una imagen irreal de Argentina que se propagaba en Polonia. En repetidas ocasiones tanto "Głos Polski" como "Niezależny Kurier Polski w Argentynie" denunciaban que, pese a la extremadamente difícil situación, el Sindicato Emigratorio en Polonia difundía una falsa información sobre la escasez de la mano de obra en Argentina e informaba que las organizaciones polacas radicadas en este país solicitaban a las autoridades el envío urgente de los trabajadores del mismo origen ("Głos Polski”, no 1162, 17.11.1934: 1). En uno de los artículos publicados en el año 1933 podemos leer:

El contexto actual nos hace mirar de forma más crítica el problema de nuestra emigración y evidencia la necesidad del cambio en materia de la política [emigratoria] (...). Desde la recuperación de la independencia, los movimientos emigratorios cobraron carácter masivo. Se pudo observar el despoblamiento de algunos pueblos y una acelerada venta de parcelas con el fin de conseguir el dinero suficiente para financiar el viaje [hacia Argentina] (...). [Hasta hace poco] todos ganaban bastante bien, algunos incluso, con pequeños ahorros, pudieron retornar al país (...). Estos tiempos desgraciadamente ya pasaron. Todavía hay gente en Polonia que cree que Argentina es una mina de oro. (...) Muchos de los que llegaron en los últimos dos años confirman que los 
motivos de su emigración se debían a esta imagen (...). Hoy en día, tienen que enfrentarse a los fantasmas de la desocupación, miseria y pésimas condiciones de vida. [traducción de la autora]

(“Kalendarz Polski” 1932: 117-118)

Efectivamente, si revisamos las publicaciones de la época, la Argentina aparece, invariablemente, como un país de grandes oportunidades e inmensas riquezas naturales, todavía sin explotar, que están al alcance de cualquiera que se decidiera a venir y a adueñarse de ellas. Éste, por ejemplo, es el caso del libro publicado en 1929 por un viajero y periodista polaco, Mieczysław Fularski. En el capítulo titulado "Argentina - tierra prometida”, el autor enumera todos los beneficios de los que gozan los polacos tras arribar al puerto bonaerense: una buena acogida por parte de la sociedad argentina, fácil acceso al trabajo bien remunerado y, sobre todo, las innumerables posibilidades de un rápido ascenso social. Entre los consejos que Fularski les da a los futuros emigrantes, uno llama particularmente la atención: "La gente que conoce las relaciones locales asegura que entre las condiciones imprescindibles para enriquecerse en Argentina, la primera es llegar sin nada de dinero en el bolsillo" (Fularski 1929: 22).

Pese al panorama poco alentador y a las denuncias de propagar entre los futuros emigrados una visión inexacta sobre Argentina, las principales publicaciones de la comunidad polaca, leales a la línea oficial de la política emigratoria del Estado polaco, no contemplaban el regreso al país como una de las posibles soluciones para miles de desocupados. Al menos no sin que éstos hayan reunido un capital suficiente. En una serie de notas, cuya publicación coincide con el auge de la crisis, en palabras encendidas, se desalentaba a los lectores de la idea del retorno. El principal argumento pretendía convencerles de que se trataba de una situación pasajera, que estaba a punto de finalizar. En un llamamiento dirigido a los desocupados, apelando a su orgullo y al sacrificio que para ellos y para sus familias supuso el hecho de llegar hasta Argentina, podemos leer:

¡No pueden perder la fe! ¡No pueden desesperarse! ¡Tienen que lograr el objetivo con el que habían dejado el país y a su familia! No olviden que para salir del país y para comprar el billete del barco se habían gastado hasta la última moneda. Para poder viajar habian vendido la última vaca, el último pedazo de tierra o incluso habían pedido un préstamo usurario. Emigraron para asegurar su existencia y la de sus seres queridos. Es por ello que no pueden volver como náufragos, con el espíritu quebrantado $y$ sin dinero -tienen que volver tal como lo prometieron- salvando a sus familias de la miseria y convertidos en su apoyo para el futuro. [traducción de la autora]

(“Głos Polski”, no 830, 12.10.1933: 1) 


\section{La imagen del inmigrante polaco en la época de entreguerras}

Teniendo en cuenta las circunstancias anteriormente descritas, no es de extrañar que la imagen de los inmigrantes polacos residentes en Buenos Aires durante el periodo de entreguerras difícilmente pudiera catalogarse como positiva. Miles de desocupados procedentes de Polonia, subsistiendo en las proximidades del Puerto Nuevo, dependientes de la caridad, mendigando por los barrios céntricos o protagonistas de la crónica policial; éste era un cuadro frecuente y difícil de ignorar que presentaban las calles porteñas en el primer lustro de la década de los 30 . En estas circunstancias no faltaron opiniones que señalaban que las dificultades que experimentaban los polacos a la hora de incorporarse a las estructuras existentes del país eran resultado directo de la etapa preemigratoria. De acuerdo con estas ideas, el anteriormente mencionado subcomisario Ré, afirmaba: "[A partir de la I Guerra Mundial] nuestro país presenció impasible la invasión pacífica de gente extranjera, de todas las nacionalidades -especialmente polaca-, gente que en su mayoría por su condición de ex combatientes, traía consigo taras patológicas y carencia absoluta de recursos de subsistencia" (Ré 1938: 65). De esta forma, el hecho de haber pasado por las experiencias de la guerra les condenaba, según esta línea argumentativa, a ser portadores de trastornos mentales y, por tanto, imposibilitaba su integración a la sociedad argentina.

Esta imagen poco favorable se fue nutriendo también debido al creciente número de inmigrantes ilegales de origen polaco que entraban a la Argentina. El fuerte impacto de la crisis económica de los años treinta y la ola de nacionalismo que se fue expandiendo en el país ${ }^{3}$ provocaron la adopción de nuevas modificaciones en la legislación migratoria. Primero, se procedió a elevar las tasas consulares y, en 1932, la entrada al país fue condicionada a estar en posesión de un contrato de trabajo. Si bien se permitía el ingreso de aquellos que fuesen llamados por sus parientes, el permiso de desembarco era concedido solo en el caso de que estos últimos estuvieran en condiciones de costear la subsistencia de los recién llegados (Devoto 2009). Dichas restricciones originaron, a su vez, nuevas estrategias de entrada a Argentina. En estas circunstancias, no faltaron personas que viajaban primero a Paraguay, país vecino con política migratoria menos restrictiva, para luego, de manera ilegal, cruzar la frontera (Międzynarodowe Towarzystwo Osadnicze 1938).

Otro de los ámbitos en los que el gentilicio polaco fue ganando una fama importante, aunque no necesariamente deseada por los integrantes de la comunidad, era la prostitución. A finales del siglo XIX y principios del XX se

3 El 6 de setiembre de 1930 se efectuó en Buenos Aires el golpe de Estado, encabezado por el general José Feliz Uriburu, simpatizante de los fascismos europeos. Los golpistas nuclearon a su alrededor a los grupos más intransigentes de la derecha nacionalista y a los sectores tradicionales del conservadurismo (Macor 2009: 53).
La emigración polaca hacia la Argentina de entreguerras

Katarzyna Porada 
registró un importante grado de masculinización de la población, resultado directo de la llegada de miles de inmigrantes, en su mayoría hombres solos o solteros, que contribuyó a la propagación de las llamadas "casas alegres". Respondiendo a la demanda existente, en 1906, en la ciudad de Buenos Aires, fue creada la que en pocos años se convertiría en la más poderosa organización de prostitución y trata de blancas en todo el continente latinoamericano: "La Sociedad Israelita de Socorros Mutuos Varsovia". La referencia a la capital polaca era una particular forma de homenajear el lugar de origen de los socios fundadores, en su mayoría judíos procedentes de Polonia. Posteriormente, en el año 1927, tras la intervención del cuerpo diplomático polaco, empeñado en defender, al menos a nivel nominal, "el buen nombre y la reputación del país", la organización pasó a denominarse la "Sociedad de Socorros Mutuos, Sinagoga y Cementerio Zwi Migdal” (Yafitz 2011).

Durante años de su lucrativo funcionamiento, la red de proxenetas se dedicó a introducir en el país -en Buenos Aires primero, y luego en Rosario, Córdoba, Mendoza, Tucumán y Corrientes- a miles de mujeres provenientes principalmente de la Europa Centrooriental. Tentadas con falsas promesas de mejorar la situación vivida en sus pueblos natales, tras arribar a la Argentina, las víctimas terminaban en alguno de los prostíbulos a cargo de los socios de la "Zwi Migdal" (Alsogaray 1930). La expansión en Buenos Aires de los prostíbulos, propiedad de los judíos oriundos de Polonia, y una gran presencia de las prostitutas del mismo origen contribuyeron a que el gentilicio polaco fuera a menudo utilizado como equivalente del rufián, y la polaca como sinónimo de prostituta. Aunque la red fue desmantelada en 1930, la asociación entre la inmigración polaca y la prostitución persistió en el imaginario colectivo durante varias décadas.

La particular mala fama que se habían ganado los ciudadanos polacos en Buenos Aires fue comprobada por los representantes de los medios de comunicación polacos. Según afirmaba Konrad Wrzos, uno de los más destacados periodistas de la época de entreguerras, de visita en la Argentina en 1936: “... al lector de la prensa argentina no le sorprende que junto con el apellido de una prostituta asesinada, de un tratante de blancas arrestado, de un asesino en busca y captura o de un ladrón, se encuentre una corta descripción: polaco" [traducción de la autora] (Wrzos 1937: 47). También la prensa comunitaria demostraba una clara preocupación por esta imagen poco halagüeña y frecuentemente publicaba quejas de los lectores denunciando el abuso policial. Según los actores involucrados, era habitual que los funcionarios detuvieran o propiciaran una paliza a los ciudadanos polacos, sin otro motivo aparente que su origen. En consecuencia, frente a los prejuicios existentes, muchos de los polacos residentes en Buenos Aires optaban por hacerse pasar por representantes de cualquier otra nacionalidad, antes que confesar su verdadera procedencia (“Głos Polski”, no 892, 27.12.1933: 5).

Por último, no faltaron acusaciones de que la comunidad polaca agrupaba a numerosos "comunistas", "revolucionarios" o "elementos subversivos". Según los voceros del grupo, esta vez también se trataba de imputaciones totalmente injustificadas y que, otra vez, comprobaban la existencia de un complot orga- 
nizado en contra del Estado polaco y de sus ciudadanos. En un llamamiento publicado en "Głos Polski", se alentaba a todos los ciudadanos polacos a defender el buen nombre de la comunidad:

Antes que nada, tenemos que convencer a la prensa de nuestra segunda patria-Argentina que la emigración polaca hacia Argentina es, en su mayoría, apolítica, que está compuesta en un 99\% de campesinos, con una cultura mínima, que en Polonia nunca participaron en la vida político-social y llegaron hasta aquí exclusivamente en busca de la manutención y pensando en asegurar su futuro, es decir, para trabajar. La opinión de que el gobierno polaco intencionalmente se deshace de "elementos revolucionarios", incitándolos a la emigración, es totalmente falsa. [traducción de la autora]

(“Głos Polski”, no 867, 27.11.1933: 1)

Independientemente de lo acertado de la opinión sobre las intenciones encubiertas de las autoridades polacas, el fragmento muestra un hecho significativo. Como podemos ver, a los ojos de los dirigentes comunitarios era preferible pasar por personas sin educación, ignorantes, portadores de una "cultura mínima" y sin ninguna experiencia en la vida política, que ser acusados de "elementos revolucionarios" o, en el peor de los casos, de "comunistas".

\section{A modo de conclusión}

Como se ha pretendido demostrar, los años de entreguerras, y particularmente la primera mitad de la década de los 30, fue un período muy difícil para la comunidad polaca radicada en Argentina. Si bien los ciudadanos polacos no eran los únicos perjudicados por la crisis económica de le época, llama poderosamente la atención el porqué de su alta vulnerabilidad en el contexto argentino. En un intento de contestar este interrogante, en primer lugar, habría que señalar las ya mencionadas políticas proemigratorias promovidas por el Estado polaco y el mínimo apoyo que los emigrados recibían una vez arribados en el país de destino. El proceso migratorio a gran escala, abiertamente promovido y patrocinado por las autoridades polacas, superó numéricamente las etapas anteriores. Los años del auge migratorio polaco coincidieron en el tiempo con la época anterior a la crisis económica mundial. Al tratarse de una inmigración relativamente joven, sus estructuras colectivas no alcanzaron la capacidad de brindar ayuda suficiente a los connacionales más necesitados. Consecuentemente, sin empleo, sin ahorros y con un apoyo institucional insuficiente, miles de ciudadanos polacos pasaron a poblar los asentamientos de desocupados que empezaron a hacerse presentes en el paisaje urbano bonaerense.

Por otro lado, además de los factores arriba señalados, la respuesta a la pregunta planteada la encontramos, en parte, en el perfil de los propios
La emigración polaca hacia la Argentina de entreguerras

Katarzyna Porada 
emigrados. La gran mayoría eran obreros no calificados, peones o jornaleros, carentes de oficio y sin competencias técnicas suficientes como para garantizar el acceso a un empleo estable. Dentro de este grupo, algunos encontraban trabajo en fábricas, talleres, frigoríficos ubicados en el cono suburbano; otros, en cuadrillas de peones destinadas a la construcción de las vías ferroviarias, y los demás eran requeridos en el campo, durante la época de cosecha. No obstante, al agravarse la situación laboral en la Argentina, se convertían en mano de obra prescindible y, en consecuencia, eran los primeros en perder el trabajo.

La situación descrita perduró hacia la segunda mitad de los años treinta. A partir de entonces se produjo una paulatina recuperación económica de la Argentina, lo que favoreció, a su vez, la afluencia del capital extranjero. El mercado laboral volvió a restablecerse y la desocupación, incluida la de los ciudadanos polacos, fue disminuyendo. Junto con las condiciones económicas empezó a recuperarse el movimiento migratorio entre ambos países. Ya en 1936, aproximadamente 6 mil ciudadanos polacos arribaron a Buenos Aires, y un año más tarde, este número creció hasta 8,5 mil (Smolana 1983: 56). No obstante, el estallido de la Segunda Guerra Mundial paralizó casi por completo los movimientos poblacionales, poniendo fin a una época destacable en la historia de la migración polaca hacia la Argentina.

\section{Referencias bibliográficas}

Alsogaray J. (1930), Trilogía de la trata de blancas: rufianes, policía, municipalidad, Tor, Buenos Aires.

Ballent A., Goreli A. (2001), País urbano o país rural: la modernización territorial y su crisis, en: A. Cattaruzza, (dir.), Crisis económica, avance del estado e incertidumbre política (19301943), vol. VII, Nueva historia argentina, Sudamericana, Buenos Aires, pp. 145-200.

Daniel C. (2013), De crisis a crisis: la invención de la desocupación en la Argentina, "Revista de Indias", vol. LXXIII, no 257, pp. 193-218.

Devoto F. (2009), Historia de la inmigración en la Argentina, Editorial Sudamericana, Buenos Aires.

Federacja Towarzystw i Org. Dom Polski (1935), Sprawozdanie i Bilans Generalny. Rok 1935, Federacja Towarzystw i Org. Dom Polski, Buenos Aires.

Fularski M. (1929), Argentyna-Paragwaj-Boliwia. Wrażenia z podróży, Świat, Warszawa.

Girbal Blacha N. (2003), La Junta Nacional Para Combatir la Desocupación. Tradición y modernización socioeconómica en los años treinta, "Revista Estudios del Trabajo", no 25, pp. 25-53.

Janowska H. (1984), Emigracja $z$ Polski $w$ latach 1918-1939, en: Emigracja $z$ ziem polskich $w$ czasach nowożytnych i najnowszych (XVIII-XX w.), A. Pilch (ed.), Państwowe Wydawnictwo Naukowe, Warszawa, pp. 326-450.

Junta Nacional para Combatir la Desocupación (1938), Memoria Elevada al Ministerio del Interior: 1936-1937, Compañía Impresora Argentina, Buenos Aires. 
Klarner-Kosińska I. (1983), Polonia w Buenos Aires, en: Dzieje Polonii w Ameryce Łacińskie: zbiór studiów, M. Kula, (ed.), Zakład Narodowy im. Ossolińskich, Wrocław, pp. 218-243.

Korol J. C. (2001), La economía, en: A. Cattaruzza, (dir.), Nueva historia argentina, vol. VII: Crisis económica, avance del Estado e incertidumbre política (1930-1943), Sudamericana, Buenos Aires, pp. 17-45.

Macor D. (2009), Partidos, coaliciones y sistema de poder, en: A. Cattaruzza, (dir.), Nueva historia argentina, vol. VII: Crisis económica, avance del Estado e incertidumbre política (1930-1943), Sudamericana, Buenos Aires, pp. 49-95.

Mazurek J. (2006), Kraj a emigracja. Ruch ludowy wobec wychodźstwa chłopskiego do krajów Ameryki Łacińskiej (do 1939 roku), Instytut Studiów Iberyjskich i Iberoamerykańskich Uniwersytetu Warszawskiego i Muzeum Historii Polskiego Ruchu Ludowego w Warszawie, Warszawa.

Międzynarodowe Towarzystwo Osadnicze (1938), Pismo Międzynarodowego Towarzystwa Osadniczego do Ministerstwa Spraw Zagranicznych w sprawie emigracji polskiej do Paragwaju i przemytu emigrantów do Argentyny, documento publicado en: "Teki Archiwalne" no 16, 1977, por A. Pałasiewicz, Pismo Międzynarodowego Towarzystwa Osadniczego o emigracji polskiej do Paragwaju (1938), Warszawa, pp. 171-179.

Nalewajko M. (2014), Los polacos hacia América Latina. La política emigratoria del gobierno polaco en el periodo de entre guerras, en: Migraciones internacionales, actores sociales y Estados: perspectivas del análisis histórico, E. González Martínez y A. Fernández (eds.), Iberoamericana Vervuert, Madrid, pp. 129-147.

Oteiza E. (2000), Inmigración y discriminación. Políticas y Discursos, Trama Editorial, Buenos Aires.

Porada K. (2016), Procesos de formación de la identidad étnica de un grupo de origen inmigrante en Argentina. Los descendientes de polacos en Buenos Aires y Misiones, Polifemo, Madrid.

Ré J. A. (1938), El problema de la mendicidad en Buenos Aires: sus causas y remedios, Talleres Gráficos, Buenos Aires.

Smolana K. (1983), Za ocean po lepsze życie, en: Dzieje Polonii w Ameryce Łacińskiej, M. Kula (coord.), Ossolineum, Wrocław, pp. 39-63.

Snitcofsky V. L. (2013), Impactos urbanos de la gran depresión: el caso de Villa Desocupación en la ciudad de Buenos Aires (1932-1935), "Cuaderno Urbano. Espacio, Cultura, Sociedad", vol. 15 , no 15 , pp. 93-109.

Wrzos K. (1937), Yerba Mate, Wydawnictwo RÓJ, Warszawa.

Yafitz M. (2011), Prosopografía proxeneta: Inmigración judía, socorros mutuos y comercio sexual en Argentina, 1906-1930, en: Marginados y consagrados: nuevos estudios sobre la vida judía en la Argentina, E. Kahan (ed.), Lumiere, Buenos Aires, pp. 67-92.
La emigración polaca hacia la Argentina de entreguerras

Katarzyna Porada 